\title{
Contribution of Matrix Metalloproteinase-2 Promoter Genotypes to Nasopharyngeal Cancer Susceptibility and Metastasis in Taiwan
}

\author{
SHIH-WEI HSU ${ }^{1,2,3^{*}}$, CHI-LI GONG ${ }^{*}$, HUAI-MEI HSU ${ }^{1,5^{*}}$, CHIH-CHANG CHAO $^{6}$, YUN-CHI WANG $^{5}$, \\ WEN-SHIN CHANG ${ }^{5}$, YUEH-TING TSAI ${ }^{5}$, LIANG-CHUN SHIH ${ }^{1,7}$, CHIA-WEN TSAI $^{5}$ and DA-TIAN BAU ${ }^{1,5,8}$ \\ ${ }^{1}$ Graduate Institute of Biomedical Sciences and ${ }^{4}$ Department of Physiology, \\ China Medical University, Taichung, Taiwan, R.O.C.; \\ ${ }^{2}$ Taichung Armed Forces General Hospital, Taichung, Taiwan, R.O.C.; \\ ${ }^{3}$ National Defense Medical Center, Taipei, Taiwan, R.O.C.; \\ ${ }^{5}$ Terry Fox Cancer Research Laboratory, Translational Medicine Research Center \\ and ${ }^{7}$ Department of Otolaryngology, China Medical University Hospital, Taichung, Taiwan, R.O.C.; \\ ${ }^{6}$ Institute of Neurosciences, National Chengchi University, Taipei, Taiwan, R.O.C.; \\ ${ }^{8}$ Department of Bioinformatics and Medical Engineering, Asia University, Taichung, Taiwan, R.O.C.
}

\begin{abstract}
Background/Aim: Matrix metalloproteinase 2 (MMP2) is up-regulated in many cancers. However, the association of MMP2 genotype to nasopharyngeal cancer (NPC) susceptibility in Taiwan remains elusive. Materials and Methods: In this study, the role of MMP2 promoter $C-1306 T$ (rs243865) and C-735T (rs2285053) genotypes were investigated among 208 NPC patients and 416 healthy controls, and their role in NPC staging and TNM classifications were examined. Results: There was no differential distribution as for the genotypic or allelic frequencies at MMP2 promoter C-1306T or C-735T between the control and case groups. Noticeably, those with MMP2 $C-1306 T C T+T T$ genotypes had a lower metastatic risk than those with $C C(p=0.0295)$. As for staging, $T$ and $N$ classifications, there was no differential distribution in $C$ $1306 T$ genotypes $(p>0.05)$. Also, there was no differential distribution of $C-735 T$ genotypes according to different behavioral/clinicopathological characteristics. Conclusion:
\end{abstract}

This article is freely accessible online.

*These Authors contributed equally to this study.

Correspondence to: Da-Tian Bau, Terry Fox Cancer Research Laboratory, Translational Medicine Research Center, China Medical University Hospital, 2 Yuh-Der Road, Taichung, 404 Taiwan, R.O.C. Tel: +886 422053366 (Ext. 5805), e-mail: datian@mail.cmuh.org.tw; artbau2@gmail.com

Key Words: Genotype, metastasis, $M M P 2$, nasopharyngeal cancer, susceptibility, polymorphism, Taiwan.
CT and TT genotypes at MMP2 C-1306T were associated with a significantly decreased risk of NPC metastasis.

From the viewpoint of epidemiology, nasopharyngeal cancer (NPC) is the 18th most commonly occurring cancer in men and the 22nd most commonly occurring cancer in women. There were 129,000 new cases in 2018 (1). NPC is a rapidly growing squamous cell carcinoma which features distant metastasis and affects both adults and children (2). EpsteinBarr virus (EBV) infection, cigarette smoking and alcohol consumption have been reported to be environmental risk factors for NPC $(3,4)$. Only a few people develop the disease in areas where NPC is endemic even though everyone is exposed to the same environment, suggesting that genetic differences such as single nucleotide polymorphisms (SNPs) may contribute to NPC carcinogenesis. However, the molecular mechanism of NPC induced by these factors is still unknown. Increasing knowledge of the genomics of NPC may lead to the discovery of novel biomarkers for the early detection and prediction of NPC susceptibility and also patients' prognosis.

Extracellular matrix (ECM) structures play an important role in providing biochemical support of surrounding cells and in regulating micro-environmental remodeling during tumorigenesis (5). The matrix metalloproteinases (MMPs), also known as matrixins, are a family of calcium-dependent zinc-containing endopeptidases involved in ECM remodeling via controlling the degradation of the ECM components such as the connective tissue matrices $(5,6)$. In literature, MMPs, especially MMP2, were reported to be related to the regulation of NPC invasion and metastasis $(7,8)$. 
Table I. Demographic characteristics of the investigated 208 nasopharyngeal carcinoma patients and 416 non-cancer healthy controls.

\begin{tabular}{|c|c|c|c|c|c|c|c|}
\hline \multirow[t]{2}{*}{ Characteristics } & \multicolumn{3}{|c|}{ Controls $(\mathrm{n}=416)$} & \multicolumn{3}{|c|}{ Cases $(n=208)$} & \multirow[t]{2}{*}{$p$-Value } \\
\hline & $\mathrm{n}$ & $\%$ & Mean (SD) & $\mathrm{n}$ & $\%$ & Mean (SD) & \\
\hline Age $(y)$ & & & $49.7(12.2)$ & & & $49.3(11.4)$ & $0.7434^{\mathrm{b}}$ \\
\hline Gender & & & & & & & $1.0000^{\mathrm{a}}$ \\
\hline Male & 304 & $73.1 \%$ & & 152 & $73.1 \%$ & & \\
\hline Female & 112 & $26.9 \%$ & & 56 & $26.9 \%$ & & \\
\hline \multicolumn{8}{|l|}{ Behavioral habits } \\
\hline Cigarette smokers & 157 & $37.7 \%$ & & 87 & $41.8 \%$ & & $0.3241^{\mathrm{a}}$ \\
\hline Alcohol drinkers & 130 & $31.3 \%$ & & 73 & $35.1 \%$ & & $0.3337^{\mathrm{a}}$ \\
\hline Areca chewers & 118 & $28.4 \%$ & & 64 & $30.8 \%$ & & $0.5334^{\mathrm{a}}$ \\
\hline \multicolumn{8}{|l|}{ Clinical stage, $\mathrm{n}, \%$} \\
\hline I and II & & & & 88 & $42.3 \%$ & & \\
\hline III and IV & & & & 120 & $57.7 \%$ & & \\
\hline \multicolumn{8}{|c|}{ Local tumor invasion ( $\mathrm{T}$ classification) } \\
\hline I and II & & & & 147 & $70.7 \%$ & & \\
\hline III and IV & & & & 61 & $29.3 \%$ & & \\
\hline \multicolumn{8}{|c|}{ Lymph node involvement ( $\mathrm{N}$ classification) } \\
\hline N0 and N1 & & & & 145 & $69.7 \%$ & & \\
\hline $\mathrm{N} 2$ and $\mathrm{N} 3$ & & & & 63 & $30.3 \%$ & & \\
\hline \multicolumn{8}{|c|}{ Distance metastasis (M classification) } \\
\hline M0 & & & & 177 & $85.1 \%$ & & \\
\hline M1 & & & & 31 & $14.9 \%$ & & \\
\hline
\end{tabular}

SD: Standard deviation; aAnalyzed by Chi-square test; bAnalyzed by unpaired Student's $t$-test.

MMP2 gene is located on chromosome $16 \mathrm{q} 21$ and is composed of 12 introns and 13 exons (9). The $M M P 2$ promoter C-1306T (rs243865) and C-735T (rs2285053) polymorphisms can affect expression of both mRNA and protein by altering its transcriptional activity, and eventually contributing to the development of several types of cancer, including breast, lung, esophageal and colon cancer (10-13). Also, MMP2 has been reported to be up-regulated in patients with oral squamous cell carcinoma, especially those with lymph node metastasis (14). In 2013, Huang and his colleagues reported that NPC cells had a higher rate of MMP2 expression in tumor metastases than in the primary cervical tumor (15). Thus, the present case-control genotyping study was performed to investigate the correlations of MMP2 promoter C-1306T (rs243865) and C-735T (rs2285053) polymorphisms with the susceptibility and metastatic potential of NPC in Taiwan.

\section{Materials and Methods}

Nasopharyngeal cancer patient and control groups collection. The current study was approved by the Institutional Review Board (DMR101-IRB1-306) of our Hospital. First, two hundred and eight patients diagnosed with NPC voluntarily provided $5 \mathrm{ml}$ of their peripheral blood and completed a self-administered questionnaire. Then, for each case, two age- and gender-matched healthy controls, who had no NPC or other types of cancer, were selected from those attending the hospital for a health examination. Thus, a total of 416 non-cancer healthy individuals were selected as controls by matching for age and gender after initial random sampling from the
Health Examination Cohort of the hospital. They contributed blood and completed the questionnaire. The questionnaire administered to each participant included questions on family history, frequency of alcohol consumption, areca chewing and smoking habit. Selfreported alcohol consumption, areca chewing and smoking habits were evaluated and classified as categorical variables. Information on these factors was obtained more than twice a week for many years. The male versus female ratio was $73.1 \%$ to $26.9 \%$ in each group, perfectly matched with each other. The recurrence and metastasis status of each patient was closely followed up at least twice per year after surgery. The mean age of the patients and the controls was $49.3(\mathrm{SD}=11.4)$ and $49.7 \quad(\mathrm{SD}=12.2)$ years, respectively, showing that the matching was successful causing a non-significant differential distribution between the case and control groups. More detailed information is summarized in Table I.

Genotyping processes. The genomic DNA from the peripheral blood leucocytes donated by each participant was prepared within $24 \mathrm{~h}$ after collection by using the QIAamp Blood Mini Kit (Blossom, Taipei, Taiwan), and stored at $-80^{\circ} \mathrm{C}$ until processed, as per our previous articles (3-5). In this study, the genotypes at C-1306T and $\mathrm{C}-735 \mathrm{~T}$ polymorphic sites in the $M M P 2$ promoter region were determined for all the subjects in both the control and NPC patient groups. In brief, the polymorphic sites were genotyped by typical polymerase chain reaction-restriction fragment length polymorphism (PCR-RFLP) methodologies using the BioRad Mycycler (BioRad, Hercules, CA, USA) (16-20). Each PCR reaction consisted of a 5 min initial cycle at $94^{\circ} \mathrm{C}$ for $5 \mathrm{~min} ; 40$ cycles of $94^{\circ} \mathrm{C}$ for $30 \mathrm{sec}$, $55^{\circ} \mathrm{C}$ for $30 \mathrm{sec}$, and $72^{\circ} \mathrm{C}$ for $30 \mathrm{sec}$; and a final extension at $72^{\circ} \mathrm{C}$ for $10 \mathrm{~min}$. After PCR, the SNP-containing DNA amplicons were subjected to individual overnight digestion by restriction 
Table II. Distribution of matrix metalloproteinase-2 (MMP2) genotypes among the investigated 208 nasopharyngeal carcinoma patients and 416 non-cancer healthy controls.

\begin{tabular}{|c|c|c|c|c|c|c|}
\hline & \multicolumn{2}{|c|}{ Controls } & \multicolumn{2}{|c|}{ Cases } & \multirow[t]{2}{*}{ OR $(95 \% \mathrm{CI})$} & \multirow[t]{2}{*}{$p$-Value ${ }^{\mathrm{a}}$} \\
\hline & $\mathrm{n}$ & $\%$ & $\mathrm{n}$ & $\%$ & & \\
\hline \multicolumn{7}{|c|}{$M M P 2 \mathrm{C}-1306 \mathrm{~T}$} \\
\hline $\mathrm{CC}$ & 287 & $69.0 \%$ & 147 & $70.7 \%$ & 1.00 (Reference) & \\
\hline $\mathrm{CT}$ & 121 & $29.1 \%$ & 55 & $26.4 \%$ & $0.89(0.61-1.29)$ & 0.5332 \\
\hline $\mathrm{TT}$ & 8 & $1.9 \%$ & 6 & $2.9 \%$ & $1.46(0.50-4.30)$ & 0.4853 \\
\hline $\begin{array}{c}P_{\text {trend }} \\
M M P 2 \mathrm{C}\end{array}$ & & & & & & 0.6152 \\
\hline $\mathrm{CC}$ & 278 & $66.8 \%$ & 135 & $64.9 \%$ & 1.00 (Reference) & \\
\hline $\mathrm{CT}$ & 119 & $28.6 \%$ & 65 & $31.3 \%$ & $1.12(0.78-1.62)$ & 0.5283 \\
\hline $\mathrm{TT}$ & 19 & $4.6 \%$ & 8 & $3.8 \%$ & $0.87(0.37-2.03)$ & 0.7424 \\
\hline$P_{\text {trend }}$ & & & & & & 0.7509 \\
\hline
\end{tabular}

aAnalyzed by Chi-square test without Yates' correction.

Table III. Distribution of allelic frequencies for matrix metalloproteinase-2 (MMP2) among patients with nasopharyngeal carcinoma and non-cancer controls.

\begin{tabular}{|c|c|c|c|c|c|c|}
\hline & Controls, $\mathrm{n}$ & $\%$ & Cases, $\mathrm{n}$ & $\%$ & OR $(95 \% \mathrm{CI})$ & $p$-Value ${ }^{\mathrm{a}}$ \\
\hline \multicolumn{7}{|c|}{$M M P 2 \mathrm{C}-1306 \mathrm{~T}$} \\
\hline $\mathrm{C}$ & 695 & $83.5 \%$ & 349 & $83.9 \%$ & 1.00 (Reference) & \\
\hline $\mathrm{T}$ & 137 & $16.5 \%$ & 67 & $16.1 \%$ & $0.97(0.71-1.34)$ & 0.8710 \\
\hline \multicolumn{7}{|c|}{$M M P 2$ C-735T } \\
\hline $\mathrm{C}$ & 675 & $81.1 \%$ & 335 & $80.5 \%$ & 1.00 (Reference) & \\
\hline $\mathrm{T}$ & 157 & $18.9 \%$ & 81 & $19.5 \%$ & $1.04(0.77-1.40)$ & 0.7989 \\
\hline
\end{tabular}

aAnalyzed by Chi-square test without Yates' correction.

endonucleases. Following digestion, each sample was immediately analyzed by agarose gel electrophoresis. Genotyping was repeated by two researchers independently, and blindly, and the results were $100 \%$ concordant. Details of primer sequences and restriction enzymes are provided in Table II.

Statistical analyzing methodology. The Student's $t$-test was used for comparing the distribution of ages between the two groups. Pearson's Chi-square test was applied to compare the distribution of the MMP2 $\mathrm{C}-1306 \mathrm{~T}$ and C-735T genotypes among the subgroups, and also to examine the possible interaction among the indexes of interest. The $\mathrm{x}^{2}$ goodness-of-fit tests were performed separately for each polymorphic site to check for Hardy-Weinberg Equilibrium. The associations between the MMP2 C-1306T and C-735T genotypes and NPC risk were estimated by computing odds ratios (ORs) and their 95\% confidence intervals (CIs) from logistic regression analysis. Any difference with a $p<0.05$ was considered statistically significant.

\section{Results}

The frequency distributions of demographic indexes including age, gender, personal cigarette smoking, alcohol drinking and areca chewing habits for the 208 NPC and 416 non-cancer controls are summarized in Table I. Since frequency matching for age and gender was applied to recruit the non-cancer healthy controls, there was no difference in the distribution of age $(p=0.7434)$ and a perfect match of gender was obtained $(p=1.0000)$ between the control and case groups (Table I, top). For all the investigated individuals, a non-significant, higher percentage of cigarette smoking, alcohol drinking and areca chewing habits was found in the case group compared to the control group (all $p>0.05$ ) (Table I, top). The clinicopathological characteristics, including the clinical stages and TNM classifications, of the 208 NPC patients are presented in the bottom part of Table I.

The distributions of the $M M P 2$ promoter C-1306T and C735T genotypes among the non-cancer controls and the NPC patients are presented and statistically analyzed in Table II. The genotypes of $M M P 2$ promoter C-1306T were nondifferentially distributed between NPC and non-cancer control group ( $\mathrm{p}$ for trend=0.6152) (Table II, top). In detail, the $M M P 2$ promoter C 1306T heterozygous CT and homozygous TT were not associated with altered NPC risk 
Table IV. p-Values and odds ratios for matrix metalloproteinase-2 (MMP2) C-1306T genotypes stratified according to the clinical stages and TNM classifications.

\begin{tabular}{lccc}
\hline NPC patient status & \multicolumn{2}{c}{$M M P 2$ C-1306T genotype } & \\
\cline { 2 - 3 } & CC & CT+TT & $p$-Value \\
\hline Clinical stages & & & \\
$\quad$ Stages I and II & 64 & 24 & \\
$\quad$ Stages III and IV & 83 & 37 & 0.5773 \\
T classification & & & \\
$\quad$ Stages I and II & 99 & 48 & 0.1019 \\
$\quad$ Stages III and IV & 48 & 13 & \\
N classification & & & \\
N0 and N1 & 98 & 47 & 0.1379 \\
N2 and N3 & 49 & 14 & \\
M classification & & & \\
M0 & 120 & 57 & $0.0295^{\mathrm{b}}$ \\
M1 & 27 & 4 & \\
\hline
\end{tabular}

aThe $p$-values were calculated by the Chi-square test without Yates' correction; bStatistically recognized as significant.
Table V. p-Values and odds ratios for matrix metalloproteinase-2 (MMP2) C-735T genotypes stratified according to the clinical stages and TNM classifications.

\begin{tabular}{lccc}
\hline NPC patient status & \multicolumn{2}{c}{$M M P 2$ C-735T genotype } & \\
\cline { 2 - 3 } & CC & CT+TT & $p$-Value \\
\hline Clinical stages & & & \\
Stages I and II & 57 & 31 & \\
$\quad$ Stages III and IV & 78 & 42 & 0.9729 \\
T classification & & & \\
Stages I and II & 98 & 49 & \\
Stages III and IV & 47 & 14 & 0.1379 \\
N classification & & & \\
N0 and N1 & 93 & 52 & 0.7255 \\
N2 and N3 & 42 & 21 & \\
M classification & & & \\
M0 & 116 & 61 & 0.6471 \\
M1 & 19 & 12 & \\
\hline
\end{tabular}

aThe $p$-values were calculated by the Chi-square test without Yates' correction. $(p=0.5332$ and $0.4853, \mathrm{OR}=0.89$ and $1.46,95 \% \mathrm{CI}=0.61-1.29$ and $0.50-4.30$, respectively; Table II, top). Similarly, the genotypes of $M M P 2$ promoter C-735T were not differentially distributed between oral cancer and non-cancer control groups ( $p$ for trend $=0.7509$ ) (Table II, bottom). In detail, the MMP2 promoter $\mathrm{C} 735 \mathrm{~T}$ heterozygous $\mathrm{CT}$ and homozygous TT were not associated with altered NPC risk ( $p=0.5283$ and $0.7424, \mathrm{OR}=1.12$ and $0.87,95 \% \mathrm{CI}=0.78-1.62$ and $0.37-2.03$, respectively; Table II, bottom). The observed distributions of the genotypes $\mathrm{C} 1306 \mathrm{~T}$ and $\mathrm{C}-735 \mathrm{~T}$ of the MMP2 promoter were in Hardy-Weinberg equilibrium in both control and case groups (all $p>0.05$ ).

To confirm the findings in Table II, allelic frequency distribution analysis of the MMP2 promoter C-1306T and C$735 \mathrm{~T}$ was also conducted and the results are summarized in Table III. In accordance with the finding that CT or TT genotype of $M M P 2$ promoter $\mathrm{C}-1306 \mathrm{~T}$ was not associated with NPC risk, the variant allele $\mathrm{T}$ was found in $16.1 \%$ in the case group, not-significantly different from the $16.5 \%$ in the control group $(p=0.8710, \mathrm{OR}=0.97,95 \% \mathrm{CI}=0.71-1.34)$. It was also validated that there was no significant differential distribution $(p=0.7989, \mathrm{OR}=1.04,95 \% \mathrm{CI}=0.77-1.40)$ as for the allelic frequencies of $M M P 2$ promoter C-735T (Table IV, bottom). To sum up, there was no significant difference in the allelic frequencies of $M M P 2$ promoter $\mathrm{C}-1306 \mathrm{~T}$ or $\mathrm{C}$ $735 \mathrm{~T}$ between the control and NPC groups (Table III).

Next, we examined whether the MMP2 promoter C-1306T and C-735T genotypes could serve as markers of the clinical stages or TNM classification of the investigated Taiwanese NPC patients. Noticeably, the NPC patients carrying the genotypes $\mathrm{CT}+\mathrm{TT}$ at the $M M P 2$ promoter $\mathrm{C}-1306 \mathrm{~T}$ had a lower risk of metastasis $(p=0.0295)$ than patients carrying the wild-type CC genotype at MMP2 promoter C-1306T (Table IV, bottom). On the contrary, there was no differential distribution of the $M M P 2$ promoter C-1306T genotype among NPC patients of different clinical stages $(p=0.5773)$, T classifications $(p=0.1019)$ or $\mathrm{N}$ classifications $(p=0.1379)$ (Table IV, top). MMP2 promoter C-735T genotype was not associated with clinical stage, $\mathrm{T}, \mathrm{N}$ or $\mathrm{M}$ classification in these NPC patients (Table V).

\section{Discussion}

In the current case-control association study, the contribution of $M M P 2$ promoter C-1306 and C-735T genotypes to NPC risk was firstly evaluated in 208 Taiwanese NPC patients and 416 age- and gender-matched healthy control subjects. Variations in the two SNP loci, C-1306T and C-735T, both located upstream of the $M M P 2$ transcriptional start site, might destroy the binding site of Sp1, resulting in a decrease in transcription, and eventually a decrease in MMP2 protein expression levels (21). In literature, there are already two case-control studies investigating the contribution of MMP2 genotypes to head and neck (HNC) cancer $(22,23)$. In 2004, Lin and his colleagues reported that the $\mathrm{CC}$ genotype frequency at $M M P 2 \mathrm{C}-1306 \mathrm{~T}$ was significantly higher in oral squamous cell carcinoma (OSCC) cases than in controls $(p=0.04)$ (22). Consistently, O-Charoenrat and colleagues have found that the $\mathrm{T}$ allele frequencies were significantly lower in the patient compared to the control group (6.9\% 
versus $12.8 \%$ and $p<0.05)$. Moreover, they have also found that $M M P 2$ expression in $\mathrm{HNC}$ cells containing the $\mathrm{CC}$ genotype was significantly higher than that in cells with the CT genotype (23). In 2018, our team found that the variant $\mathrm{T}$ allele at MMP2 $\mathrm{C}-1306 \mathrm{~T}$ conferred lower oral cancer susceptibility than the wild-type $\mathrm{C}$ allele (24). Although sample size (control:case $=288 / 242$ and 496/478, 956/788, respectively) was similar to the one in the current study focused on the investigation of NPC, our conclusion should be validated with more studies. The current study showed that although the genotypes at MMP2 C-1306 or C-735T cannot serve as predictors of NPC risk in Taiwan (Tables II and III), the variant $\mathrm{CT}$ and TT genotypes at MMP2 C$1306 \mathrm{~T}$ were associated with significantly decreased risk of NPC metastasis (Table IV).

The MMP2 protein, also named gelatinase, plays a significant role in the degradation of various substrates, such as fibrillar collagen, elastin, endothelin, fibroblast growth factor, MMP-9, MMP-13, plasminogen, and TGF- $\beta$ (25). The degradation of ECM by MMP2 is an important step in the invasion and metastasis processes (26, 27). Overexpressed and activated MMP2 is observed and reported to be associated with poor prognosis of many types of cancer including melanoma, colorectal, breast, ovarian, lung and prostate cancer (28)

Overall, the $\mathrm{C}$ allele at $M M P 2 \mathrm{C}-1306 \mathrm{~T}$ contributes to higher mRNA and protein levels of MMP2 compared to the $\mathrm{T}$ allele. Moreover, elevated levels of active MMP2 is thought to promote epithelial-mesenchymal transition via the degradation of type IV collagen, the most abundant component of the basement membrane. The breakage of the basement membrane is an essential step in the invasion and metastasis of cancer cells (29). Thus, as shown in Table IV, NPC patients carrying the genotypes CT and TT at $M M P 2$ promoter C-1306T had lower risk of metastasis than patients carrying the $\mathrm{CC}$ genotype. In the precision medicine era, the current finding is beneficial for NPC patients carrying the CC genotype at their MMP2 C-1306T, as they can be followed-up more frequently than those with the CT and CT genotypes, since they have an increased risk of metastasis. This close follow-up may be helpful in lowering the rate of NPC metastases and possibly reduce mortality.

In conclusion, the variant $\mathrm{CT}$ and TT genotypes at $M M P 2$ promoter $\mathrm{C}-1306 \mathrm{~T}$ may not serve as a protective biomarker for determining susceptibility to NPC, but may serve as a very effective predictor of NPC metastatic behavior. The role of this functional SNP in NPC needs further investigation and the temporary conclusion of this study should be validated in more populations.

\section{Conflicts of Interest}

The Authors declare no conflicts of interest in regard to this study.

\section{Authors' Contributions}

Research Design: Hsu SW and Gong CL; Patient and Questionnaire Summarize: Hsu SW and Shih LC; Experiment Performance: Hsu HM, Wang YC and Chang WS; Statistical Analysis: Chao CC, Tsai YT; Manuscript Writing: Tsai CW and Bau DT; Reviewing and Revising: Bau DT, Chang WS and Tsai CW.

\section{Acknowledgements}

The Authors appreciate the Tissue-bank of China Medical University Hospital for their excellent sample collection, and $\mathrm{Su}-\mathrm{Yi}$ Pan, Chia-Wen Lin, Cin-Wun Wu, Chia-Yi Pan and Chi-Hsuan Cheng for their technical assistance. This study was supported mainly by the Taichung Armed Forces General Hospital to Dr. Hsu (106A17) and Taiwan Ministry of Science and Technology to Professor Bau (MOST-106-2320-B-039-035).

\section{References}

1 Bray F, Ferlay J, Soerjomataram I, Siegel RL, Torre LA and Jemal A: Global cancer statistics 2018: GLOBOCAN estimates of incidence and mortality worldwide for 36 cancers in 185 countries. CA Cancer J Clin 68: 394-424, 2018. PMID: 30207593. DOI: $10.3322 /$ caac. 21492

2 Lin CL, Lo WF, Lee TH, Ren Y, Hwang SL, Cheng YF, Chen CL, Chang YS, Lee SP, Rickinson AB and Tam PK: Immunization with Epstein-Barr Virus (EBV) peptide-pulsed dendritic cells induces functional $\mathrm{CD} 8^{+} \mathrm{T}$-cell immunity and may lead to tumor regression in patients with EBV-positive nasopharyngeal carcinoma. Cancer Res 62: 6952-6958, 2002. PMID: 12460912.

3 O'Neil JD, Owen TJ, Wood VH, Date KL, Valentine R, Chukwuma MB, Arrand JR, Dawson CW and Young LS: Epstein-Barr virus-encoded EBNA1 modulates the AP-1 transcription factor pathway in nasopharyngeal carcinoma cells and enhances angiogenesis in vitro. J Gen Virol 89: 2833-2842, 2008. PMID: 18931081. DOI: 10.1099/vir.0.2008/003392-0

4 Cheng YJ, Hildesheim A, Hsu MM, Chen IH, Brinton LA, Levine PH, Chen CJ and Yang CS: Cigarette smoking, alcohol consumption and risk of nasopharyngeal carcinoma in Taiwan. Cancer Causes Control 10: 201-207, 1999. PMID: 10454065.

5 Woessner JF Jr.: Matrix metalloproteinases and their inhibitors in connective tissue remodeling. FASEB J 5: 2145-2154, 1991. PMID: 1850705.

6 Murphy G and Docherty AJ: The matrix metalloproteinases and their inhibitors. Am J Respir Cell Mol Biol 7: 120-125, 1992. PMID: 1497900. DOI: 10.1165/ajrcmb/7.2.120

7 Zhang $X$ and Zhuang R: Dione-thiophene conjugate inhibits proliferation and metastasis of nasopharyngeal carcinoma cells through calcium binding protein-P down-regulation. Eur J Med Chem 168: 199-206, 2019. PMID: 30822709. DOI: 10.1016/ j.ejmech.2019.01.051

8 Yang J, Lv X, Chen J, Xie C, Xia W, Jiang C, Zeng T, Ye Y, Ke L, Yu Y, Liang H, Guan XY, Guo X and Xiang Y: CCL2CCR2 axis promotes metastasis of nasopharyngeal carcinoma by activating ERK1/2-MMP2/9 pathway. Oncotarget 7: 15632-15647, 2016. PMID: 26701209. DOI: 10.18632/ oncotarget.6695 
9 Ye S: Polymorphism in matrix metalloproteinase gene promoters: implication in regulation of gene expression and susceptibility of various diseases. Matrix Biol 19: 623-629, 2000. PMID: 11102751.

10 Waleh NS, Murphy BJ and Zaveri NT: Increase in tissue inhibitor of metalloproteinase-2 (TIMP-2) levels and inhibition of MMP-2 activity in a metastatic breast cancer cell line by an anti-invasive small molecule SR13179. Cancer Lett 289: 111118, 2010. PMID: 19751965. DOI: 10.1016/j.canlet.2009.08.006

11 Bourboulia D, Han H, Jensen-Taubman S, Gavil N, Isaac B, Wei B, Neckers L and Stetler-Stevenson WG: TIMP-2 modulates cancer cell transcriptional profile and enhances E-cadherin/betacatenin complex expression in A549 lung cancer cells. Oncotarget 4: 166-176, 2013. PMID: 23371049. DOI: 10.18632/ oncotarget.801

12 Groblewska M, Mroczko B, Kozlowski M, Niklinski J, Laudanski $\mathrm{J}$ and Szmitkowski M: Serum matrix metalloproteinase 2 and tissue inhibitor of matrix metalloproteinases 2 in esophageal cancer patients. Folia Histochem Cytobiol 50: 590-598, 2012. PMID: 23264224. DOI: 10.5603/20327

13 Kapral M, Wawszczyk J, Jurzak M, Dymitruk D and Weglarz L: Evaluation of the expression of metalloproteinases 2 and 9 and their tissue inhibitors in colon cancer cells treated with phytic acid. Acta Pol Pharm 67: 625-629, 2010. PMID: 21229878.

14 Patel BP, Shah PM, Rawal UM, Desai AA, Shah SV, Rawal RM and Patel PS: Activation of MMP-2 and MMP-9 in patients with oral squamous cell carcinoma. J Surg Oncol 90: 81-88, 2005. PMID: 15844188 . DOI: $10.1002 /$ jso.20240

15 Huang T, Chen MH, Wu MY and Wu XY: Correlation between expression of extracellular matrix metalloproteinase inducer and matrix metalloproteinase- 2 and cervical lymph node metastasis of nasopharyngeal carcinoma. Ann Otol Rhinol Laryngol 122: 210215, 2013. PMID: 23577575. DOI: 10.1177/00034 8941312200311

16 Hsu PC, Pei JS, Chen CC, Chang WS, Kuo CC, Cheng SP, Tsai CW, Bau DT and Gong CL: Association of matrix metallopeptidase-2 promoter polymorphisms with the risk of childhood leukemia. Anticancer Res 39: 1185-1190, 2019. PMID: 30842148. DOI: 10.21873/anticanres.13228

17 Shen TC, Chang WS, Tsai CW, Chao CY, Lin YT, Hsiao CL, Hsu CL, Chen WC, Hsia TC and Bau DT: The contribution of matrix metalloproteinase-1 promoter genotypes in Taiwan lung cancer risk. Anticancer Res 38: 253-257, 2018. PMID: 29277780. DOI: 10.21873 /anticanres. 12215

18 Shih LC, Li CH, Sun KT, Chen LY, Hsu CL, Hung YW, Wu CN, Hsia TC, Shen TC, Chang WS, Shih TC, Tsai CW and Bau DT: Association of matrix metalloproteinase-7 genotypes to the risk of oral cancer in Taiwan. Anticancer Res 38: 2087-2092, 2018. PMID: 29599326. DOI: 10.21873/anticanres.12448

19 Tsai TH, Wang YM, Chang WS, Tsai CW, Wu HC, Hsu HM, Wang YC, Li HT, Gong CL, Bau DT and Li CY: Association of matrix metalloproteinase- 8 genotypes with the risk of bladder cancer. Anticancer Res 38: 5159-5164, 2018. PMID: 30194163. DOI: 10.21873 /anticanres. 12838
20 Yueh TC, Wu CN, Hung YW, Chang WS, Fu CK, Pei JS, Wu MH, Lai YL, Lee YM, Yen ST, Li HT, Tsai CW and Bau DT: The contribution of MMP-7 genotypes to colorectal cancer susceptibility in Taiwan. Cancer Genomics Proteomics 15: 207212, 2018. PMID: 29695403. DOI: 10.21873/cgp.20079

21 Srivastava P, Pandey S, Mittal B and Mittal RD: No Association of Matrix Metalloproteinase [MMP]-2 $(-735 \mathrm{C}>\mathrm{T})$ and tissue inhibitor of metalloproteinase [TIMP]-2 $(-418 \mathrm{G}>\mathrm{C})$ gene polymorphisms with cervical cancer susceptibility. Indian J Clin Biochem 28: 13-18, 2013. PMID: 24381415. DOI: 10.1007/ s12291-012-0237-4

22 Lin SC, Lo SS, Liu CJ, Chung MY, Huang JW and Chang KW: Functional genotype in matrix metalloproteinases-2 promoter is a risk factor for oral carcinogenesis. J Oral Pathol Med 33: 405409, 2004. PMID: 15250832. DOI: 10.1111/j.1600-0714.2004. 00231.x

23 P OC and Khantapura P: The role of genetic polymorphisms in the promoters of the matrix metalloproteinase- 2 and tissue inhibitor of metalloproteinase-2 genes in head and neck cancer. Oral Oncol 42: 257-267, 2006. PMID: 16275157. DOI: 10.1016/ j.oraloncology.2005.07.008

24 Tsai CW, Hsu HM, Wang YC, Chang WS, Shih LC, Sun KT, Hung YW, Yang YC, Gong CL and Bau DT: Contribution of MMP2 promoter genotypes to oral cancer susceptibility, recurrence and metastasis in Taiwan. Anticancer Res 38: 68216826, 2018. PMID: 30504396. DOI: 10.21873/anticanres. 13055

25 Nagase H and Woessner JF Jr.: Matrix metalloproteinases. J Biol Chem 274: 21491-21494, 1999. PMID: 10419448. DOI: $10.1074 / \mathrm{jbc} .274 .31 .21491$

26 Kessenbrock K, Plaks V and Werb Z: Matrix metalloproteinases: regulators of the tumor microenvironment. Cell 141: 52-67, 2010. PMID: 20371345. DOI: 10.1016/j.cell.2010.03.015

27 Roy R, Yang J and Moses MA: Matrix metalloproteinases as novel biomarkers and potential therapeutic targets in human cancer. J Clin Oncol 27: 5287-5297, 2009. PMID: 19738110. DOI: $10.1200 / \mathrm{JCO} .2009 .23 .5556$

28 Bjorklund $\mathrm{M}$ and Koivunen E: Gelatinase-mediated migration and invasion of cancer cells. Biochim Biophys Acta 1755: 3769, 2005. PMID: 15907591. DOI: 10.1016/j.bbcan.2005.03.001

29 Mook OR, Frederiks WM and Van Noorden CJ: The role of gelatinases in colorectal cancer progression and metastasis. Biochim Biophys Acta 1705: 69-89, 2004. PMID: 15588763. DOI: $10.1016 /$ j.bbcan.2004.09.006 